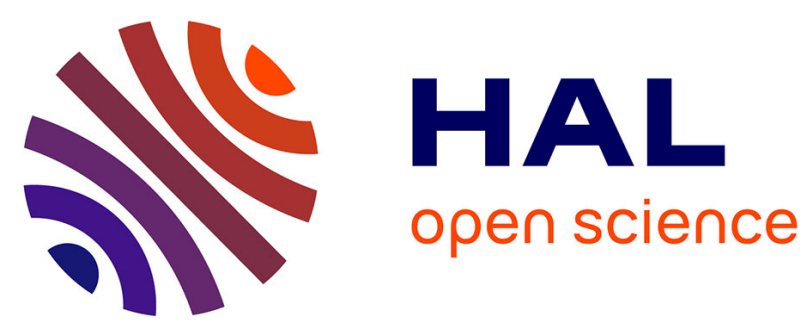

\title{
Characterization of the martensitic transformation in the superelastic Ti-24Nb-4Zr-8Sn alloy by in situ synchrotron X-ray diffraction and dynamic mechanical analysis.
}

Y. Yang, P. Castany, M. Cornen, F. Prima, S. J. Li, Y. L. Hao, T. Gloriant

\section{To cite this version:}

Y. Yang, P. Castany, M. Cornen, F. Prima, S. J. Li, et al.. Characterization of the martensitic transformation in the superelastic Ti-24Nb-4Zr-8Sn alloy by in situ synchrotron X-ray diffraction and dynamic mechanical analysis.. Acta Materialia, 2015, 88, pp.25-33. 10.1016/j.actamat.2015.01.039 . hal-01153403

HAL Id: hal-01153403

https://hal-univ-rennes1.archives-ouvertes.fr/hal-01153403

Submitted on 27 Aug 2018

HAL is a multi-disciplinary open access archive for the deposit and dissemination of scientific research documents, whether they are published or not. The documents may come from teaching and research institutions in France or abroad, or from public or private research centers.
L'archive ouverte pluridisciplinaire HAL, est destinée au dépôt et à la diffusion de documents scientifiques de niveau recherche, publiés ou non, émanant des établissements d'enseignement et de recherche français ou étrangers, des laboratoires publics ou privés. 


\title{
Characterization of the martensitic transformation in the
}

\section{superelastic Ti-24Nb-4Zr-8Sn alloy by in situ synchrotron X-ray diffraction and dynamic mechanical analysis}

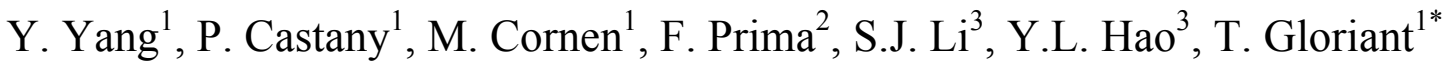 \\ ${ }^{1}$ Institut des Sciences Chimiques de Rennes, UMR CNRS 6226, INSA Rennes, 20 \\ avenue des Buttes de Coësmes, 35708 Rennes cedex 07, France \\ ${ }^{2}$ Institut de Recherche de Chimie Paris, UMR CNRS 8247, Chimie ParisTech, 11 rue \\ Pierre et Marie Curie, 75231 Paris cedex 05, France \\ ${ }^{3}$ Institute of Metal Research, Chinese Academy of Sciences, 72 Wenhua Road, \\ 110016 Shenyang, China \\ *Corresponding author: Thierry.Gloriant@insa-rennes.fr
}

\begin{abstract}
:
In this work, the martensitic transformation occurring in the superelastic Ti-24Nb-4Zr-8Sn alloy was investigated by tensile tests, in situ synchrotron X-ray diffraction (SXRD) and dynamic mechanical analysis (DMA). The SXRD results clearly showed the diffraction peaks related to the $\alpha^{\prime \prime}$ and $\beta$ phases and their evolution, under loading and unloading conditions, have highlighted the reversible stress-induced martensitic (SIM) transformation. Consequently, a three steps deformation sequence was established from both SXRD analysis and tensile test characterization. On the other hand, the characteristic temperatures related to the martensitic transformation under different applied stresses have been determined from the storage modulus and the damping curves by DMA analysis. A very good accordance concerning the critical stress inducing the martensitic transformation was obtained by comparing the results obtained from SXRD, DMA and tensile tests.
\end{abstract}

Keywords: titanium alloy, martensitic transformation, tensile tests, synchrotron diffraction, DMA 


\section{Introduction}

In this study, the metastable $\beta$-type Ti-24Nb-4Zr-8Sn (wt.\%, Ti2448 for short) alloy was investigated in order to characterize the martensitic transformation occurring in this alloy. Indeed, due to this martensitic transformation, the Ti2448 alloy shows good superelasticity at room temperature characterized by a large recoverable strain of $3.3 \%[1-3]$. This recoverable strain is much higher than that observed in the conventional Ti-6Al-4V alloy and in other binary $\mathrm{Ti}-\mathrm{Nb}$ superelastic alloys $[4,5]$. Thus, the good mechanical properties of the $\mathrm{Ti}-24 \mathrm{Nb}-4 \mathrm{Zr}-8 \mathrm{Sn}$ alloy, including high strength (>800 MPa), low modulus (approx. $50 \mathrm{GPa}$ ) and the superelasticity mentioned above enable it to be used as bone substitutes (implants or prostheses) for biomedical applications.

With this alloy, the superelastic (or pseudoelastic) behavior is obtained when the quenched microstructure is composed of the metastable $\beta$ phase at room temperature. In such cases, a stress-induced martensitic (SIM) transformation between the austenitic $\beta$ phase (bcc) and the martensitic $\alpha$ " phase $\alpha$ " (orthorhombic) occurs and large elastic recovery (superelasticity) can be obtained once the mechanical stress is released due to the fact that this SIM transformation is fully reversible. By tensile tests, the superelastic effect can be highlighted by the presence of a stress plateau on the tensile curve presenting thus a characteristic double-yielding behavior.

In superelastic alloys, the study of the SIM transformation is challenging due to its reversibility after the release of the stress. That is why in situ experiments are needed to characterize the SIM transformation under loading conditions. For example, conventional in situ X-ray diffraction (XRD) studies were performed on binary $\mathrm{Ti}-26 \mathrm{Nb}$ or $\mathrm{Ti}-13 \mathrm{Nb}-4 \mathrm{Mo}$ alloys (at.\%) and allowed the detection of the SIM $\alpha$ " phase transformation under loading conditions [4,6]. However, it is difficult to separate the main peaks belonging to $\beta$ and $\alpha$ " phases because of the relatively longer wavelength and the presence of both $\mathrm{K}_{\alpha 1}$ and $\mathrm{K}_{\alpha 2}$ wavelengths of conventional X-ray 
sources used in laboratories. In order to avoid these limitations, synchrotron X-ray diffraction (SXRD) can be used because of the combination of a shorter wavelength and a better monochromaticity. Thus, SXRD appears to be a very efficient method to characterize such SIM transformation and was never used to study the Ti2448 alloy in which superelasticity is predominantly due to this mechanism.

Furthermore, martensitic transformations are usually described using characteristic temperatures such as martensite start, martensite finish, austenite start and austenite finish temperatures, respectively denoted $M_{s}, M_{f}, A_{s}$ and $A_{f}[7,8]$. These temperatures can be evaluated by dynamic mechanical analysis (DMA) for different applied static stresses, and the martensitic transformation is thus generally highlighted by a drop of the dynamic elastic modulus corresponding to an increase of the damping factor $\tan \delta$ $[9,10]$.

The objective of this study is to characterize the martensitic transformation occurring in the Ti2448 alloy by both in situ synchrotron radiation X-ray diffraction (SXRD) and dynamic mechanical analysis (DMA).

\section{Materials and methods}

Hot-forged $\mathrm{Ti}-24 \mathrm{Nb}-4 \mathrm{Zr}-8 \mathrm{Sn}(\mathrm{wt} . \%)$ cylinder ingot with a diameter of $55 \mathrm{~mm}$ was used as raw material in this work. The chemical composition of the alloy is listed in Table 1. Each slice-cut sample used was directly cold rolled without intermediate annealing into $0.5 \mathrm{~mm}$ final thickness sheet, which corresponds to a cold rolling reduction rate of $94 \%$. Then, two thermal treatments were performed for comparison: on the one hand, cold-rolled specimens were solution treated at $900{ }^{\circ} \mathrm{C}$ under high vacuum for 30 min followed by water quenching (solution treated state, ST); on the other hand, cold-rolled specimens were flash treated at $700{ }^{\circ} \mathrm{C}$ for 3 min followed by air cooling (flash treated state, FT). After thermal treatments, all specimens were 
cleaned in an acid solution made of $50 \% \mathrm{HF}$ and $50 \% \mathrm{HNO}_{3}$ (in volume) to remove any oxidation layer.

Microstructures were observed by optical microscopy (Leica microscope). To be observed, the specimens were mechanically prepared and finally "mirror" polished using a colloidal silica suspension solution. To reveal the microstructure, each specimen was etched in an acid solution composed of $8 \% \mathrm{HF}, 15 \% \mathrm{HNO}_{3}$ and $77 \%$ $\mathrm{H}_{2} \mathrm{O}$ (in volume).

The mechanical properties of the Ti2448 alloy (ST and FT states) were evaluated by conventional tensile tests until rupture using an INSTRON 3369 tensile machine with a strain control mode at a rate of $10^{-4} \mathrm{~s}^{-1}$. To check the reproducibility of the mechanical properties, conventional tensile tests were performed on 3 different samples for each state. The superelasticity was more precisely characterized by cyclic loading-unloading tensile tests using the same tensile machine (strain control mode at a rate of $10^{-4} \mathrm{~s}^{-1}$ for both loading and unloading). With these kinds of tests, the strain was incremented by steps of $0.5 \%$ until an elongation of $5 \%$ and each step was followed by a total release of the stress. The tensile direction of the specimen was chosen parallel to the rolling direction. The tensile specimens used have a gauge width of $3 \mathrm{~mm}$ and a thickness of $0.5 \mathrm{~mm}$.

In situ synchrotron X-ray diffraction (SXRD) under cyclic tensile tests was conducted on beam line ID31 at the European Synchrotron Radiation Facility (ESRF, Grenoble, France). For these in situ tensile tests, a $5 \mathrm{KN}$ Gatan micro-tensile dispositive was used. The ID31 offers a high-resolution incident X-ray beam $(\lambda=0.040002106 \mathrm{~nm})$. Nine-channel multi-analyzer installed as detectors can collect scanning data over the angular range $2-14^{\circ}$, with a scanning step of $0.005^{\circ}$. These in situ cyclic tensile tests under synchrotron were realized on tensile specimens (gauge width of $3 \mathrm{~mm}$ and a thickness of $0.5 \mathrm{~mm}$ ) with increments of $0.5 \%$ until $5.0 \%$ and then increments of 
$1.0 \%$ until $10 \%$. SXRD scans were then obtained after each increment for both loading and unloading conditions.

Dynamic mechanical analysis (DMA) was done with a Metravib DMA50 in tensile mode. Samples for DMA were cut with a low-speed diamond wire saw. The cooling/heating thermal cycle was chosen between $-150{ }^{\circ} \mathrm{C}$ and $50{ }^{\circ} \mathrm{C}$ with a rate of 5 ${ }^{\circ} \mathrm{C} / \mathrm{min}$. The frequency of the sinusoidal dynamic mechanical solicitation was fixed at

$1 \mathrm{~Hz}$ and the dynamic/static ratio was kept at $\sigma_{\text {dyn }} / \sigma_{\text {stat }}=1 / 4$. The tests were performed with the tensile direction parallel to the rolling direction for different static stress values: 160, 200, 240 and $280 \mathrm{MPa}$. Two important characteristic parameters of the DMA analysis: storage modulus (E') and damping factor ( $\tan \delta)$ as a function of temperature can be obtained by this method. The determination of characteristic transformation temperatures is based on intersection of tangents from the curves obtained.

\section{Results}

\subsection{Microstructure and mechanical properties}

The microstructures of the Ti2448 alloy observed by optical microscopy are shown in Fig. 1 for the solution treated alloy (ST, Fig. 1a) and for the flash treated alloy (FT, Fig. 1b), respectively. The grain sizes after ST and FT were evaluated to be about $50 \mu \mathrm{m}$ and $7 \mu \mathrm{m}$ on these micrographs, respectively.

Fig. 2 displays examples of conventional and cyclic tensile curves for the ST (Fig. 2a) and FT (Fig. 2b) conditions. From all tensile tests, elongation at rupture, ultimate tensile strength and incipient Young's modulus were measured to be $10 \pm 2 \%$, $870 \pm 20 \mathrm{MPa}$ and $56 \pm 6 \mathrm{GPa}$ for ST and $9 \pm 2 \%, 990 \pm 30 \mathrm{MPa}$ and $59 \pm 8 \mathrm{GPa}$ for FT, respectively. There is no obvious variation for both ductility and Young's modulus for the two thermal conditions. Only higher strength is obtained for the FT condition due 
to the reduced grain size observed. On these tensile curves, a double yielding phenomenon associated with the superelastic effect was observed, suggesting that the SIM transformation has occurred for both ST and FT conditions. The first yielding corresponds to the critical stress inducing the SIM transformation, which is experimentally determined at the end of the linear part on each tensile curve as shown in Fig. 2. Thus, the critical stress to induce the SIM transformation was measured to be $410 \pm 10 \mathrm{MPa}$ for ST and $440 \pm 10 \mathrm{MPa}$ for FT, respectively. The highest recoverable strain of $2.75 \%$ is obtained for the FT while $2.3 \%$ maximum is reached for the ST. The higher value of recoverable strain for the FT sample was attributed to grain refinement in a recent work [11].

\subsection{In situ synchrotron X-ray diffraction}

For obtaining a direct evidence of the SIM transformation and further the crystallographic information of both $\beta$ and $\alpha$ " phases during all the deformation stages, in situ SXRD during cyclic loading/unloading tensile tests were conducted. The whole angle range spectrums at $0 \%$ strain and after $10 \%$ strain are first displayed in Fig. 3a for the ST sample and Fig. 3b for the FT sample, respectively. Before any deformation, both ST and FT samples display only the $\beta$ phase and its typical diffraction peaks: $(110)_{\beta},(200)_{\beta},(211)_{\beta}$ and $(220)_{\beta}$ as shown in Fig. 3a and b. But after being deformed up to $10 \%$, the diffraction peaks $(020)_{\alpha "},(002)_{\alpha "},(111)_{\alpha ",}$

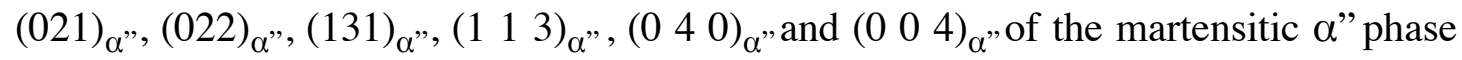
are well detected in both ST and FT samples, which coexist with residual $\beta$ phase. Thus, stress-induced martensitic transformation was clearly evidenced for both ST and FT alloys.

In order to characterize more precisely the SIM transformation, Fig. 4 displays the SXRD patterns obtained during the in situ cyclic tensile tests: on the ST sample after loading (Fig. 4a) and after each unloading (Fig. 4b) and on the FT sample after loading (Fig. 4c) and after each unloading (Fig. 4d). The different strains reached are 
indicated beside the spectra. In these figures, only the partial spectra in the angle range $8-11.5^{\circ}$ around the main $(110)_{\beta}$ peak, where the most intense peaks are present, are shown.

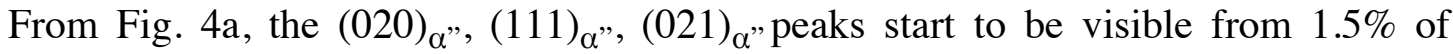
strain and their intensities continue to increase as the applied strain increases. At the same time, the $(110)_{\beta}$ peak intensity decreases meaning that the SIM transformation has occurred on loading in the ST alloy. After unloading (Fig. 4b), it can be clearly observed that all the martensitic $\alpha$ " phase could be transformed back to the $\beta$ phase as the $(110)_{\beta}$ peak intensity is recovered while the $\alpha$ " peaks disappear.

The SIM transformation and its reversibility is also evidenced in the FT alloy (Fig. 4c and d) with the difference that in this case, the SIM transformation seems to start later as the $\alpha$ " peaks start to be visible at about $2 \%$ on loading. These values are in good agreement with the tensile curve results.

From the loading spectra (Fig. 4a and c), a clear shift to the lower angles of the $\alpha$ " and $\beta$ peaks due to cell parameter variations can also be observed. Thus, from each SXRD spectrum, the angular positions of all peaks were determined to evaluate the different cell parameters and their variations under loading. The evolution of these cell parameters $\left(\mathrm{a}_{\beta}, \mathrm{a}_{\alpha "}, \mathrm{~b}_{\alpha}\right.$, and $\mathrm{c}_{\alpha}$ ") were plotted as a function of the applied percentage strain for the ST alloy (Fig. 5a) and the FT alloy (Fig. 5b), respectively.

\subsection{Dynamic mechanical analysis}

Fig. 6 displays the evolution of the storage modulus (E') and the damping factor (tan $\delta$ ) upon cooling and heating as a function of temperature under various applied stresses for the Ti2448 alloy after ST (Fig. 6a) and after FT (Fig. 6b). On these figures, E' curves are presented in black and tan $\delta$ curves in red. On cooling, E' and 
$\tan \delta$ curves are represented with solid circles, while on heating, they are represented with open circles. The applied static stress $\left(\sigma_{\text {stat }}\right)$ was initially fixed at $160 \mathrm{MPa}$ and then was subsequently increased by $40 \mathrm{MPa}$ after each temperature cycle until 280 MPa on the same specimen. All the figures show that both the martensitic transformation on cooling and the austenitic transformation on heating are characterized by a decrease of the storage modulus and an increase of the damping factor. Thus, modulus drops and damping peaks are clearly observed.

In order to characterize the martensitic transformation in the present case, the martensite start $\left(\mathrm{M}_{\mathrm{s}}\right)$ and austenite finish $\left(\mathrm{A}_{\mathrm{f}}\right)$ temperatures can be evaluated on the E' curves. The characteristic temperature of $\mathrm{M}_{\mathrm{s}}$ is the point at which the change of slope on the E' curves occurs, and also corresponds exactly to the initial increasing point on $\tan \delta$ curve upon cooling, while the $\mathrm{A}_{\mathrm{f}}$ is determined on E' curves upon heating. Other detected characteristic temperatures are $\mathrm{M}_{\max }$ and $\mathrm{A}_{\max }$, which correspond to the maximum SIM $\alpha$ " transformation.

Therefore, all the detected characteristic temperatures $M_{s}, M_{\max }, A_{f}$, and $A_{\max }$ were plotted as a function of the applied stress in Fig. 7 for the ST alloy (Fig. 7a) and for the FT alloy (Fig. 7b). As shown, a quite good linear fitting can be obtained in good agreement with the Clausius-Clapeyron relationship. It can be found that the slope is $0.19 \mathrm{~K} / \mathrm{MPa}$ for $\mathrm{M}_{\mathrm{s}}$ and $\mathrm{M}_{\max }, 0.32 \mathrm{~K} / \mathrm{MPa}$ for $\mathrm{A}_{\mathrm{f}}$ and $0.24 \mathrm{~K} / \mathrm{MPa}$ for $\mathrm{A}_{\max }$ for the $\mathrm{ST}$ sample. On the other hand, all the slopes were found to be $0.20-0.22 \mathrm{~K} / \mathrm{MPa}$ for the FT sample.

\section{Discussion}

From the evolution of the different cell parameters determined by SXRD (Fig. 5), it 
can be observed firstly that the $\beta$ phase is elastically deformed in the $0-2.0 \%$ strain range (Fig. 5a) and in the $0-2.5 \%$ strain range (Fig. 5b) for ST and FT alloys, respectively. As shown, the $\mathrm{a}_{\beta}$ increases from 3.30 to $3.33 \AA$ (in ST alloy) and from 3.30 to $3.34 \AA$ (in FT alloy). On the other hand, once the $\alpha$ " phase appears, this phase is observed to be elastically deformed up to $4.5 \%$ for ST and 5\% for FT, respectively. This elastic deformation is clearly observed to be accommodated by an increase of the

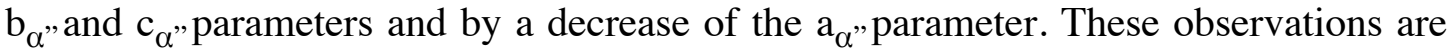
in agreement with the tensile curves. Consequently, from both SXRD analysis and tensile tests, a three-step deformation sequence can be established as follows: firstly, the $\beta$ phase is elastically deformed up to around $1.5-2 \%$ of strain in the ST alloy (2-2.5\% for FT alloy); secondly, the deformation is accommodated by the SIM $\alpha$ " transformation, which is elastically deformed up to $4.5 \%$ in ST (5\% in FT); from this value, both residual $\beta$ phase and $\alpha$ " phase start to be deformed plastically.

From the DMA experiments, the martensitic transformation is particularly well highlighted by the tan $\delta$ curve. This kind of damping peak was commonly observed in other shape memory alloys such as $\mathrm{Ni}-\mathrm{Ti}[12,13]$, Ti-Nb based alloys [14,15] and $\mathrm{Cu}-\mathrm{Al}-\mathrm{Ni}$ alloys [16]. It is well known that the reversible SIM transformation, which is accompanied by the movements of coherent austenite/martensite interfaces, can induce mechanical energy dissipation and thus constitutes an important damping source [13]. Consequently, a clear damping peak is observed in the present case and its maximum $\left(\mathrm{P}_{\max }\right)$ corresponds more or less to $\mathrm{M}_{\max }$. The high value of damping factor Tand (0.2-0.25) due to the SIM $\alpha$ " transformation in the Ti2448 alloy (Fig. 6) shows a superior damping capacity by comparison with the other $\beta$-type $\mathrm{Ti}-\mathrm{Ta}-\mathrm{Nb}$ [14] and $\mathrm{Ti}-\mathrm{Nb}-\mathrm{Al}$ [17] alloys under the same tensile mode under $1 \mathrm{~Hz}$ frequency. On the other hand, higher damping capacity is observed for the ST sample by comparison with the FT sample. This is caused by the larger $\beta$ grain size observed in ST that permits longer distance mobility of the $\alpha " / \beta$ interfaces. 
It has to be mentioned that the $\mathrm{M}_{\mathrm{f}}$ and $\mathrm{A}_{\mathrm{s}}$ temperatures cannot be clearly detected in the present case. This is due to the fact that the damping peak includes also the contribution of martensite/martensite interface movement as it was explained in a recent work [14]. The hysteretic movement of twin boundaries between martensite variants is another important damping source to dissipate mechanical energy that can overlap the movements of the austenite/ martensite interfaces [13]. That is also for this reason that the position of $P_{\max }$ does not correspond exactly to the $M_{\max }$, especially under high applied stress.

From the tensile curves obtained at room temperature (Fig. 2), the critical stress inducing the SIM $\alpha$ " transformation was found to be $410 \pm 10 \mathrm{MPa}$ for the ST sample and $440 \pm 10 \mathrm{MPa}$ for the FT sample, respectively. From the DMA analyses, the critical stress inducing the SIM $\alpha$ " transformation at room temperature can also be obtained by extrapolating the data plotted in Fig. 7 (dot-lines). Indeed, at $20{ }^{\circ} \mathrm{C}$ the critical stress corresponding to the $\mathrm{M}_{\mathrm{s}}$ value was found to be $415 \mathrm{MPa}$ for the ST sample and $440 \mathrm{MPa}$ for the FT sample, respectively, as it is indicated in Fig. 7a and b. These critical stress values coincide perfectly with those obtained by tensile tests meaning that DMA analysis and mechanical tensile tests are in very good agreement.

In this work, the SIM $\alpha$ " transformation could be clearly evidenced by tensile tests, SXRD and DMA. However, the SIM $\alpha$ " phase morphology could not be observed in the present study although great efforts have been done by using transmission electron microscopy (TEM). Indeed, only the $\beta$ phase was observed by TEM. One reason can be due to the fact that it is well known that spontaneous strain relaxation occurs during the preparation of the thin TEM specimens and consequently the SIM $\alpha$ " phase could have been transformed back to the $\beta$ phase [18].

One another reason can be linked with very recent works concerning the presence of nanodomains in this kind of alloy [19], which were first reported by Miyazaki et al. $[20,21]$. As reported, nanodomains consist of nanosized modulated domain structure 
distributed homogeneously and randomly in the $\beta$ phase and acted as obstacles for the long-range martensitic transformation. Consequently, nanodomain observation by conventional TEM remains tricky and high resolution TEM investigations are required for such characterization.

\section{Conclusions}

In this study, the superelastic $\mathrm{Ti}-24 \mathrm{Nb}-4 \mathrm{Zr}-8 \mathrm{Sn}$ alloy was investigated by tensile tests, in situ SXRD and DMA in order to characterize the martensitic transformation. From all the characterization methods used, the following conclusions can be made:

(1) By tensile tests, the Ti2448 alloy showed low Young's modulus, high strength and good superelasticity, which enable it to be used as bone substitutes (implants or prostheses) for biomedical applications.

(2) By in situ SXRD, the typical diffraction peaks of the $\beta$ and $\alpha$ " phases during loading and unloading were clearly observed and the reversible transformation between the $\beta$ phase and the SIM $\alpha$ " phase was evidenced for both ST and FT states. On the other hand, variations of the $\beta$ and $\alpha$ " cell parameters were characterized in both loading and unloading conditions.

(3) From both SXRD analysis and tensile tests, a three step deformation sequence could be established as follows: firstly, the $\beta$ phase is elastically deformed up to around $1.5-2 \%$ of strain in the ST alloy (2-2.5\% for FT alloy); secondly, the deformation is accommodated by the SIM $\alpha$ " transformation, which is elastically deformed up to $4.5 \%$ in ST (5\% in FT); from this value, both residual $\beta$ phase and $\alpha$ " phases start to be deformed plastically.

(4) From the DMA experiments, clear damping peaks were observed and the characteristic temperatures detected $\left(\mathrm{M}_{\mathrm{s}}, \mathrm{M}_{\max }, \mathrm{A}_{\mathrm{f}}\right.$, and $\left.\mathrm{A}_{\max }\right)$ were plotted as a 
function of the applied stress. A quite good linear fitting could be obtained in agreement with the Clausius-Clapeyron relationship.

(5) Very good accordance concerning the critical stress inducing the martensitic transformation was obtained by comparing the results obtained from SXRD, DMA and conventional tensile tests.

\section{Acknowledgement}

This work was financially supported by China scholarship Council (CSC), with No. 2011-6031. We acknowledge the European Synchrotron Radiation Facility for provision of synchrotron radiation facilities and we would like to thank Yves Watier for assistance in using beamline ID31.

\section{References}

[1] Hao YL, Li SJ, Sun BB, Sui ML, Yang R. Phys Rev Lett 2007; 98: 216405.

[2] Hao YL, Li SJ, Sun SY, Zheng CY, Hu QM, Yang R. Appl Phys Lett 2005; 87: 091906.

[3] Li SJ, Cui TC, Li YL, Hao YL, Yang R. Appl Phys Lett 2008; 92: 043128.

[4] Tahara M, Kim HY, Hosoda H, Miyazaki S. Acta Mater 2009; 57: 2461.

[5] Tobe H, Kim HY, Inamura T, Hosoda H, Nam TH, Miyazaki S. J Alloys Compd 2013; 577S: S435.

[6] Al-Zain Y, Kim HY, Koyano T, Hosoda H, Nam TH, Miyazaki S. Acta Mater $2011 ; 59: 1464$.

[7] Lovey FC, Torra V. Prog Mater Sci 1999; 44:189.

[8] Otsuka K, Ren X. Prog Mater Sci 2005; 50: 511.

[9] Liu Y, Van Humbeeck J, Stalmans R, Delaey L. J Alloys Compd 1997; 247: 115. 
[10] Mercier O, Melton KN, De Préville Y. Acta Metall 1979; 27: 1467.

[11] Yang Y, Castany P, Cornen M, Thibon I, Prima F, Gloriant T. J Alloys Compd 2014; 591: 85 .

[12] Mazzolai FM, Biscarini A, Coluzzi B, Mazzolai G, Villa E, Tuissi A. Acta Mater 2007; 55: 4243.

[13] Van Humbeeck J. J Alloys Compd 2003; 355: 58.

[14] Bertrand E, Castany P, Gloriant T. Acta Mater 2013; 61: 511.

[15] Yin F, Iwasaki S, Ping D, Nagai K. Adv Mater 2006; 18:1541.

[16] Suresh N, Ramamurty U. J Alloys Compd 2008; 449: 113

[17] Inamura T, Yamamoto Y, Hosoda H, Kim HY, Miyazaki S. Acta Mater, 2010; 58: 2535

[18] Lütjering G, Williams JC, Titanium. (2nd ed.)Springer-Verlag, Berlin 2007: 141

[19] Liu JP, Wang YD, Hao YL, Wang YZ, Nie ZH, Wang D, Ren Y, Lu ZP, Wang JG, Wang HL, Hui XD, Lu N, Kim MJ, Yang R. Sci Rep, 2013; 3: 2156.

[20] Kim HY, Wei L, Kobayashi S, Tahara M, Miyazak S. Acta Mater 2013; 61: 4874 .

[21] Tahara M, Kim HY, Inamura T, Hosoda H, Miyazaki S. Acta Mater 2011; 59: 6208 . 
Table 1. Chemical composition of the hot forged Ti2448 alloy (wt $\%$ ).

\begin{tabular}{ccccc}
\hline $\mathrm{Nb}$ & $\mathrm{Zr}$ & $\mathrm{Sn}$ & $\mathrm{O}$ & $\mathrm{Ti}$ \\
\hline 23.9 & 4.05 & 8.22 & 0.16 & Bal. \\
\hline
\end{tabular}
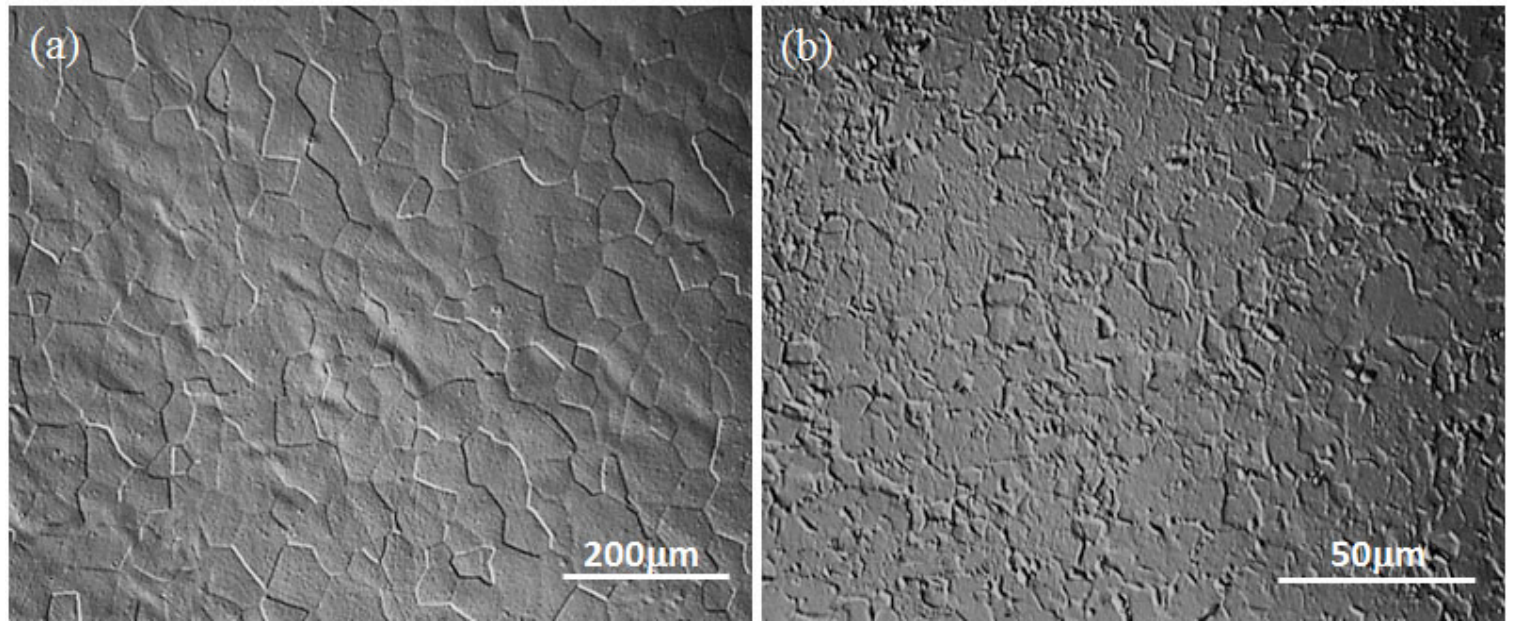

Fig. 1. Optical micrographs of the Ti2448 alloy microstructure after (a) solution treatment at $900^{\circ} \mathrm{C}$ for $30 \mathrm{~min}$ and (b) flash treatment at $700^{\circ} \mathrm{C}$ for $3 \mathrm{~min}$.
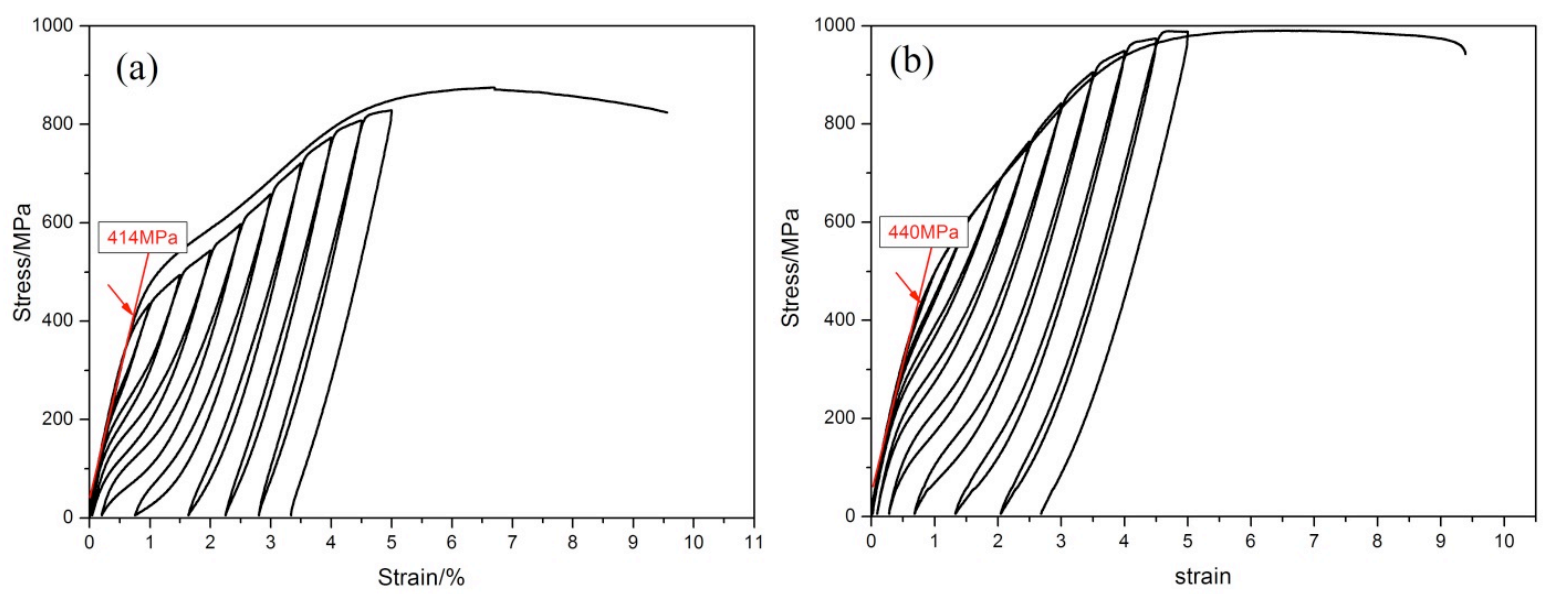

Fig. 2. Conventional and cyclic tensile strain-stress curves for the Ti2448 alloy after (a) solution treatment at $900^{\circ} \mathrm{C}$ for $30 \mathrm{~min}$ and (b) flash treatment at $700^{\circ} \mathrm{C}$ for $3 \mathrm{~min}$. 

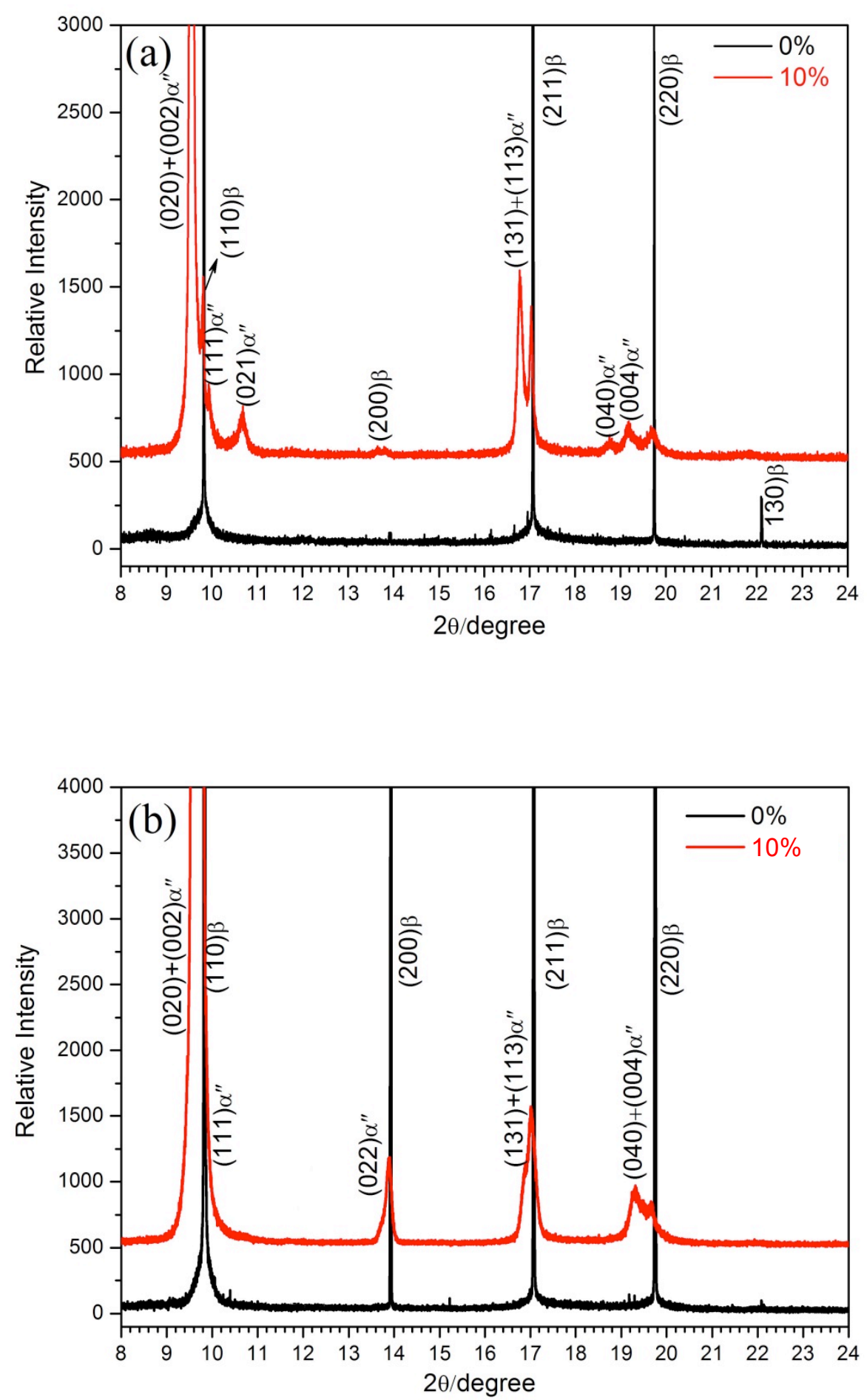

Fig. 3. In situ SXRD spectra of the Ti2448 alloy before deformation and after to be deformed at $10 \%$ of strain for ST (a) and FT (b). 

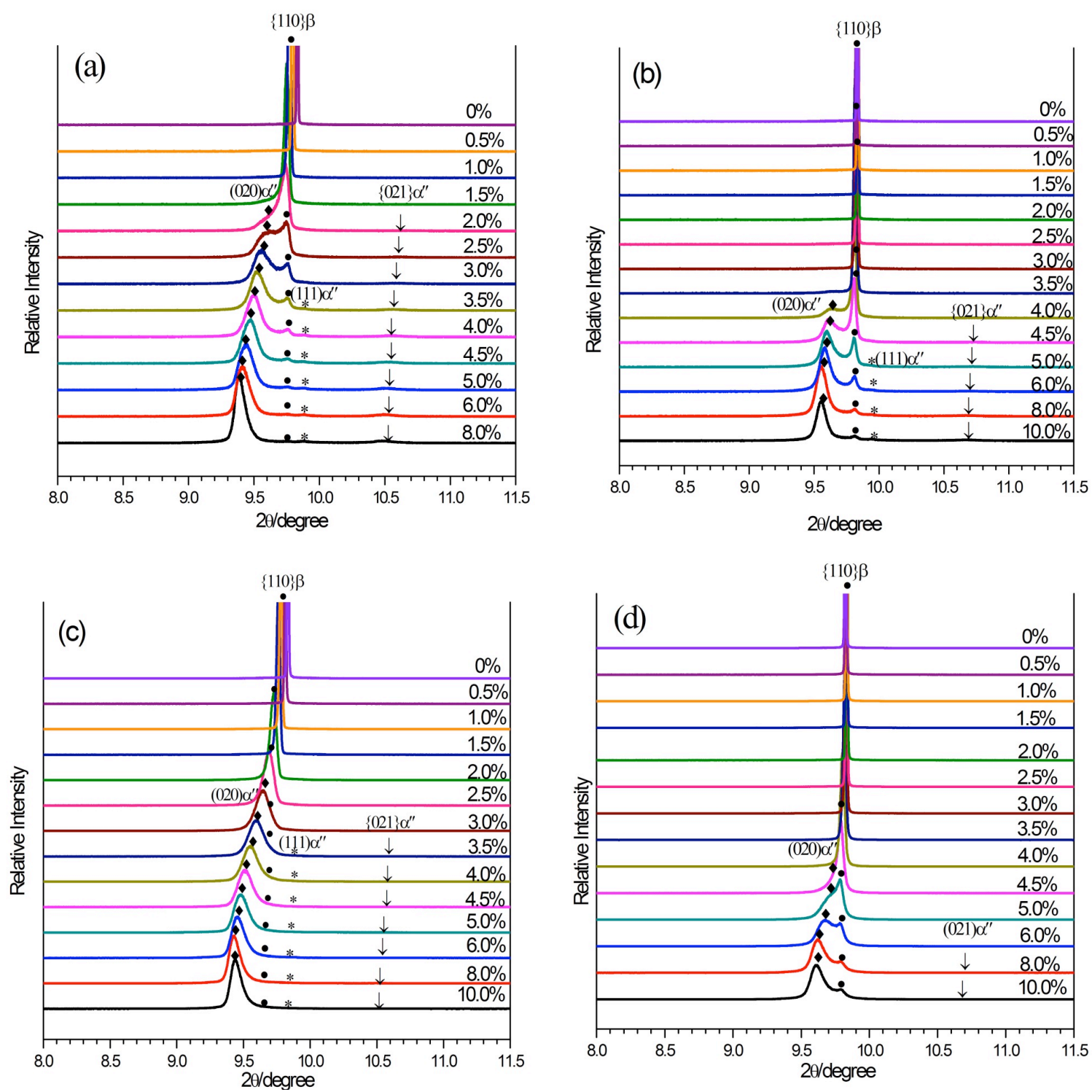

Fig. 4. The partial in situ SXRD spectra for the Ti2448 alloy on loading and after unloading for different applied strains: (a) on loading for ST sample, (b) on the corresponding unloading for ST sample, (c) on loading for FT sample and (d) on the corresponding unloading 

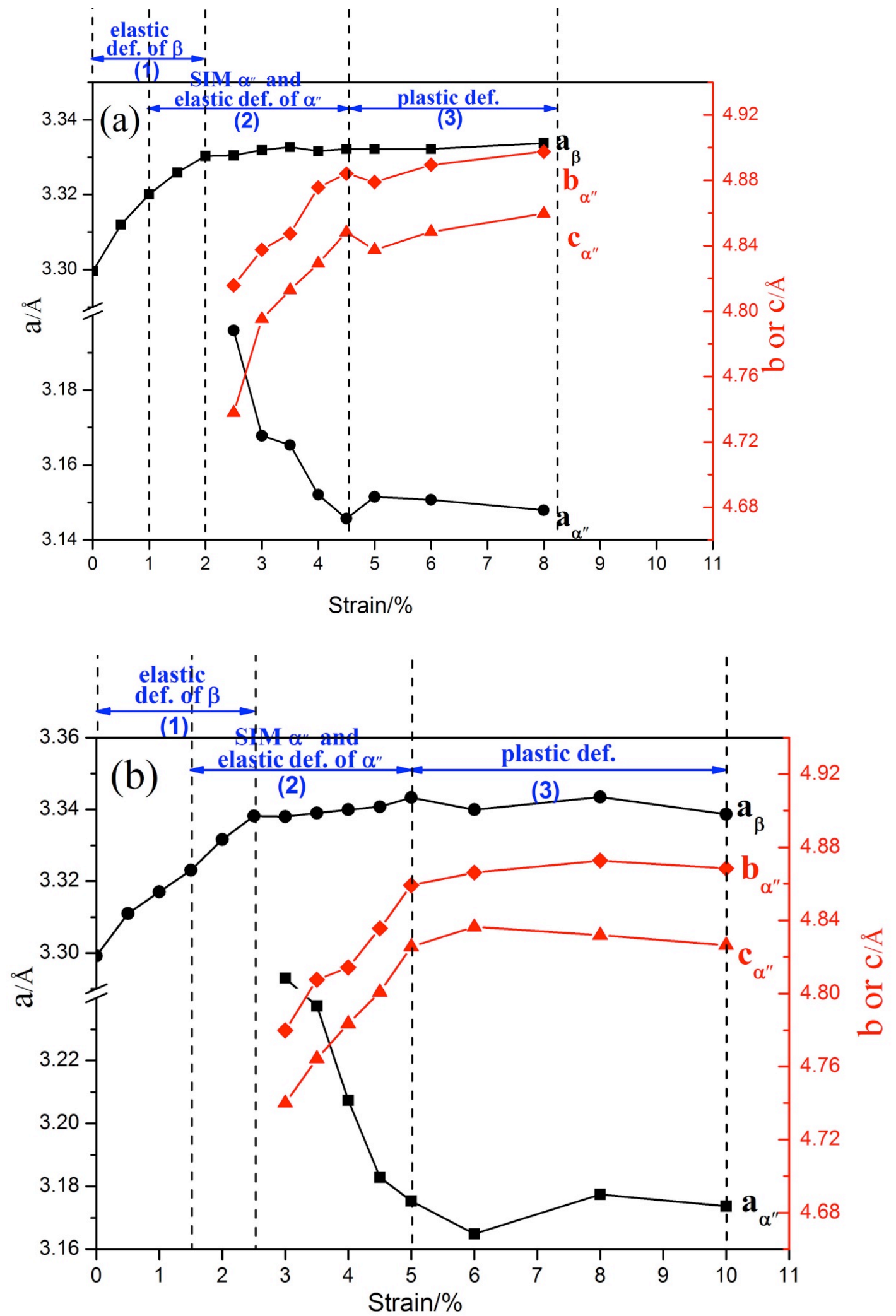

Fig. 5. The calculated cell parameters of the $\beta$ phase and $\alpha^{\prime \prime}$ phase for the Ti2448 alloy after: (a) solution treatment at $900^{\circ} \mathrm{C}$ for $30 \mathrm{~min}$ and (b) flash treatment at $700^{\circ} \mathrm{C}$ for $3 \mathrm{~min}$. 

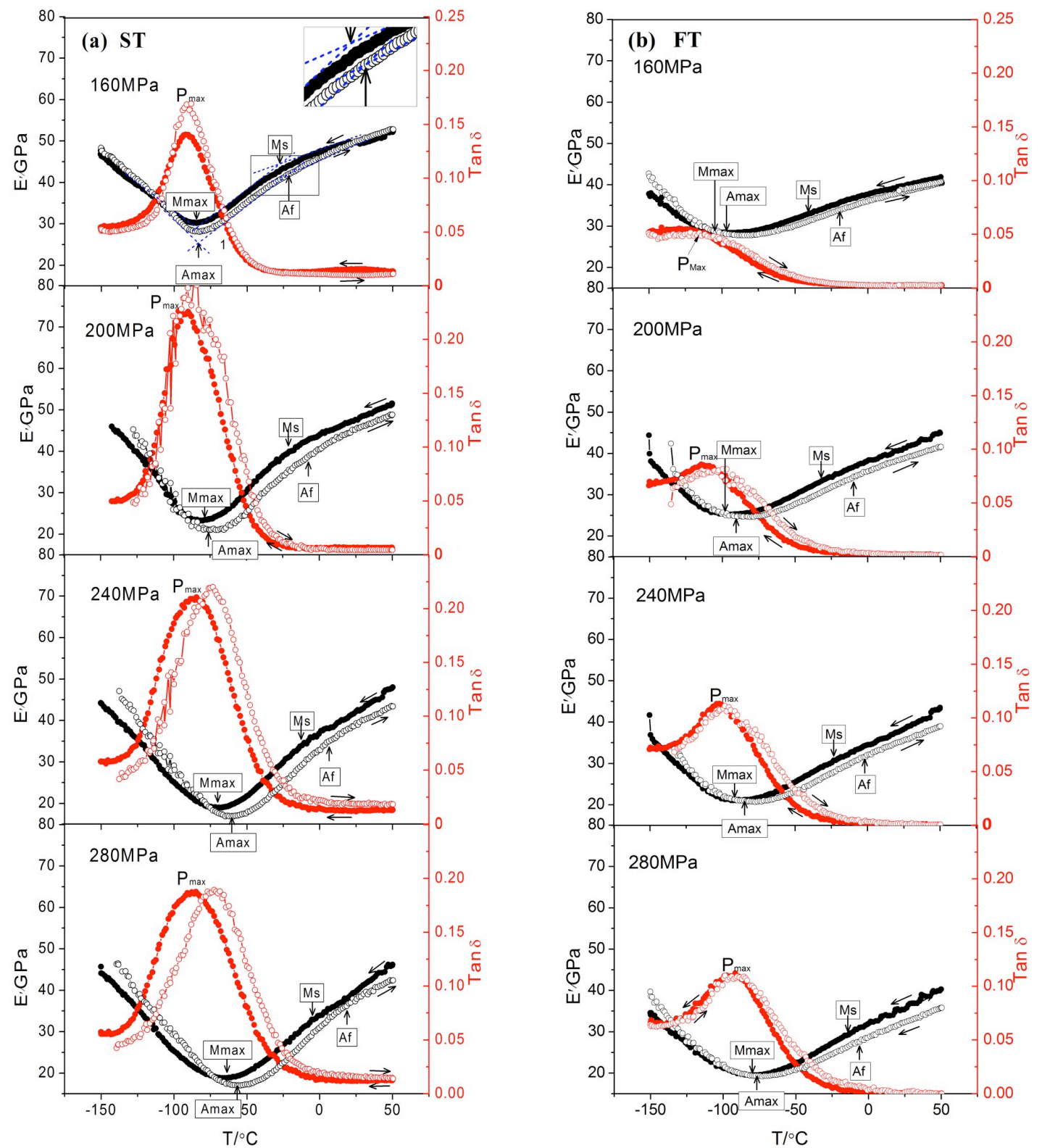

Fig. 6. Storage modulus and damping factor (in black and red, respectively) evolutions as a function of the $\sigma_{\text {stat }}$ during cooling and heating (in solid and open circles, respectively) for the Ti2448 alloy after (a) solution treatment at $900^{\circ} \mathrm{C}$ for $30 \mathrm{~min}$ and (b) flash treatment at $700^{\circ} \mathrm{C}$ for $3 \mathrm{~min}$. 

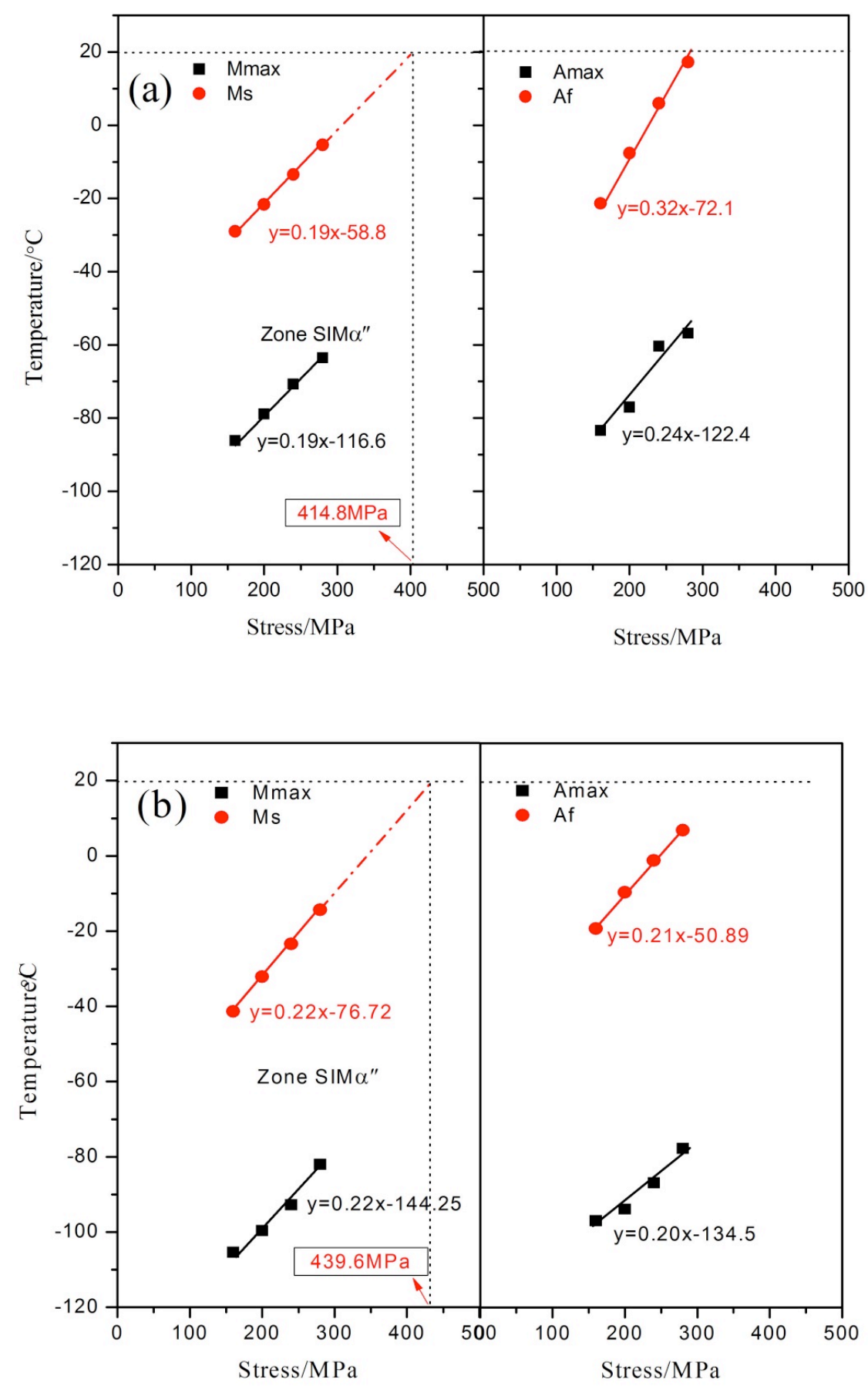

Fig. 7. Characteristic temperatures of $M_{s}, M_{\max }, A_{f}$ and $A_{\max }$ as a function of the applied static stresses $\sigma_{\text {stat }}$ for the Ti2448 alloy after different thermal treatment: (a) solution treatment at $900^{\circ} \mathrm{C}$ for $30 \mathrm{~min}$ and (b) flash treatment at $700^{\circ} \mathrm{C}$ for $3 \mathrm{~min}$. 